\title{
Expression dynamics of self-renewal factors for spermatogonial stem cells in the mouse testis
}

\author{
Mizuki SAKAI 1)*, Kaito MASAKI'², Shota AIBA ${ }^{1)}$, Masaaki TONE) and Seiji TAKASHIMA ${ }^{1,2)}$ \\ 1) Department of Applied Biology, Faculty of Textile Science and Technology, Shinshu University, Ueda 386-8567, Japan \\ 2) Department of Textile Science and Technology, Interdisciplinary Graduate School of Science and Technology, Shinshu \\ University, Ueda 386-8567, Japan
}

\begin{abstract}
Glial cell line-derived neurotrophic factor (GDNF) and fibroblast growth factor 2 (FGF2) are bona fide selfrenewal factors for spermatogonial stem cells (SSCs). Although GDNF is indispensable for the maintenance of SSCs, the role of FGF2 in the testis remains to be elucidated. To clarify this, the expression dynamics and regulatory mechanisms of $F g f 2$ and $G d n f$ in the mouse testes were analyzed. It is well known that Sertoli cells express $G d n f$, and its receptor is expressed in a subset of undifferentiated spermatogonia, including SSCs. However, we found that Fgf2 was mainly expressed in the germ cells and its receptors were expressed not only in the cultured spermatogonial cell line, but also in testicular somatic cells. Aging, hypophysectomy, retinoic acid treatment, and testicular injury induced distinct $F g f 2$ and $G d n f$ expression dynamics, suggesting a difference in the expression mechanism of $F g f 2$ and $G d n f$ in the testis. Such differences might cause a dynamic fluctuation of $G d n f / F g f 2$ ratio depending on the intrinsic/extrinsic cues. Considering that FGF2-cultured spermatogonia exhibit more differentiated phenotype than those cultured with GDNF, FGF2 might play a role distinct from that of GDNF in the testis, despite the fact that both factors are self-renewal factor for SSC in vitro.
\end{abstract}

Key words: Fibroblast growth factor 2 (FGF2), Germline niche, Glial cell line-derived neurotrophic factor (GDNF), Selfrenewal, Spermatogonial stem cell (SSC)

(J. Reprod. Dev. 64: 267-275, 2018)

$\mathbf{S}$ permatogonial stem cells (SSCs) are a special subset of undifferentiated spermatogonia and are the foundation of spermatogenesis. They adhere to the basement membrane of the seminiferous tubule, and undergo repeated self-renewal and differentiation to produce differentiating spermatogonia. These cells further amplify their population by several repeats of mitotic divisions and then enter meiotic division to produce mature spermatozoa [1].

SSCs require a specific microenvironment, often described as a germline niche, to maintain their stem cell activity. Germline niche can be described as 'the microenvironment where SSCs can maintain their undifferentiated state'. Historically and histologically, the basement membrane of the seminiferous tubule was known to form the germline niche [2]. Indeed, a cellular subset located on the basement membrane is enriched in SSCs [3]. Sertoli cells, which are somatic cells within the seminiferous tubules, are also important for SSC function by producing glial cell line-derived neurotrophic factor (GDNF) [4]. Considering that peritubular myoid cells (PMCs) produce GDNF for proper spermatogenesis, PMCs also constitute the germline niche [5]. In 2007, Yoshida et al. found that undifferentiated spermatogonia are prone to reside in a region on the basement

Received: February 6, 2018

Accepted: March 18, 2018

Published online in J-STAGE: April 16, 2018

(C)2018 by the Society for Reproduction and Development

Correspondence: S Takashima (e-mail: stakashi@shinshu-u.ac.jp)

* M Sakai and K Masaki made equal contributions to this work.

This is an open-access article distributed under the terms of the Creative Commons Attribution Non-Commercial No Derivatives (by-nc-nd) License. (CC-BY-NC-ND 4.0: https://creativecommons.org/licenses/by-nc-nd/4.0/) membrane, which is in proximity to the interstitium that contains Leydig cells and blood vessels [6]. In fact, Hara et al. observed the prowling of undifferentiated spermatogonia on the basement membrane near the interstitial tissue containing vasculature [7]. These data suggest that a specialized region of the basement membrane, in the vicinity of Sertoli cells, Leydig cells, and blood vessels, represents the germline niche. Resident macrophages surrounding the seminiferous tubules also act as a niche component by expressing colony-stimulating factor 1 (CSF1), which encodes a cytokine that accelerates SSC self-renewal $[8,9]$. As described above, the identity of the germline niche is gradually being clarified. However, it is still difficult to identify the actual location of the germline niche, because SSCs might move around in the seminiferous tubules [7].

The germline niche provides factors required for SSC self-renewal. Previous studies have reported that several cytokines, including fibroblast growth factor (FGF) 8, vascular endothelial growth factor A, wingless-type MMTV integration site family (WNT) 3A, WNT5A, and WNT6 contribute to SSC self-renewal or to the proliferation of undifferentiated spermatogonia [10-15]. Of other cytokines, GDNF was primarily confirmed to be able to induce SSC self-renewal. Meng et al. demonstrated that $G d n f$ transgenic mice exhibited hyperproliferation of undifferentiated spermatogonia, whereas $G d n f$ heterozygous mutant mice gradually lost spermatogenesis presumably due to mitotic arrest [4]. Yomogida et al. confirmed that the SSC frequency in $G d n f$ transgenic mouse testes was significantly higher than that in wild-type mouse testes by spermatogonial transplantation assay [16].

GDNF was applied to establish cultured SSC line called germline stem (GS) cells [17]. GS cells can be expanded in vitro for more than two years under stimulation with GDNF and FGF2, and can 
re-initiate spermatogenesis in infertile testes to produce offspring [18]. As reported previously, the frequency of SSCs in undifferentiated type A single spermatogonia is estimated to be 1 in 10 [19]. On the other hand, the SSC frequency in GS cell culture was estimated to be $1-2 \%$ or $-20 \%$ by spermatogonial transplantation or in vitro clonal analysis of drug-resistant genes by electroporation [20-22], suggesting that both, single spermatogonia in vivo and GS cells in vitro, possess similar SSC frequency. Moreover, GS cells, undifferentiated spermatogonia, and SSCs require GDNF signals for survival and proliferation/self-renewal [4, 16, 17, 23], suggesting that these cells share common molecular mechanisms with respect to GDNF. Indeed, this culture system has also been applied to evaluate the activity of FGF2, WNT3A, and WNT5A to expand SSCs in vitro [12-14, 24]. These reports suggest that GS cells are useful as an in vitro culture model of SSCs and undifferentiated spermatogonia.

Our group identified FGF2 as another SSC self-renewal factor [24]. We succeeded in establishing an SSC line with FGF2 under GDNF-free condition in vitro, and designated this line as FGF2cultured spermatogonia (F-SPG). F-SPG can proliferate in vitro for more than 4 months without losing SSC activity and can restore the fertility of infertile $\mathrm{Kit}^{W} / \mathrm{Kit}^{W-v}(\mathrm{~W})$ mouse, demonstrating that FGF2 is also a bona fide self-renewal factor [24]. However, our group also found functional differences between FGF2 and GDNF. F-SPG are phenotypically and functionally distinct from GDNF-cultured spermatogonia (G-SPG), in that the stem cell frequency in F-SPG is less than that in G-SPG, and F-SPG exhibit higher expression levels of the receptor tyrosine kinase protein KIT (a marker for differentiating spermatogonia) compared with G-SPG. Moreover, F-SPG and G-SPG exhibit distinct behaviors following PD0325901 (an inhibitor of mitogen-activated protein kinase (MAPK)/extracellular signal-regulated kinase kinase (MEK)) treatment. This molecule has been shown to inhibit the survival and proliferation of G-SPG, but not of F-SPG [24]. These data suggest that F-SPG exhibit the characteristics of a more differentiated subset of undifferentiated spermatogonia in vivo, compared with G-SPG and GS cells, and that FGF2 plays a role distinct from that of GDNF in the regulation of SSCs and/or undifferentiated spermatogonia in the testis.

To identify the exact role of FGF2 in the testis, it is essential to reveal its molecular function and spatiotemporal expression pattern. Here, we aimed to unveil the role of FGF2 in the testis by comparing its expression dynamics and regulatory mechanisms with those of GDNF.

\section{Materials and Methods}

\section{Mice and treatments}

Male and female C57BL/6NCrSlc (B6) mice at 8 or 52 weeks of age, and male WBB6F1/kit-Kit ${ }^{W} / K_{i t}{ }^{W-v} /$ Slc (W) mice at 8 weeks of age were purchased from Japan SLC (Shizuoka, Japan). At 7 days of age, male B6 mice were obtained by intercrossing B6 mice. For busulfan treatment, male B6 mice at 4 or 6 weeks of age were injected intraperitoneally with 44 or $15 \mathrm{mg} / \mathrm{kg}$ body weight busulfan, respectively (Sigma-Aldrich, St Louis, MO, USA). Experimental cryptorchidism was performed on 8-week-old male B6 mice, as described by Nishimune et al. [25]. Hypophysectomized, thyroidectomized, adrenalectomized, and sham-operated B6 mice were also purchased from Japan SLC; these operations were conducted at 6 weeks of age. For retinoic acid (RA) treatment, all-trans RA (Sigma-Aldrich) was dissolved in a $10 \%$ ethanol-sesame oil (Nacalai Tesque, Kyoto, Japan) solution at $3.75 \mathrm{mg} / \mathrm{ml}$ and then injected (200 $\mu \mathrm{l})$ intraperitoneally into 8 -week-old B6 mice ( $750 \mu \mathrm{g}$ per mouse). All animal experiments were approved by the Institutional Animal Care and Use Committee of Shinshu University (Approval No. 260013 and No. 280120).

\section{Preparation of testicular interstitial cells and seminiferous tubules without germ cells}

For interstitial cell enrichment, seminiferous tubules were collected from the testes of 2-month-old B6 mice treated with $44 \mathrm{mg} / \mathrm{kg}$ body weight of busulfan at 4 weeks of age. After detangling, the tubules were digested with $2 \mathrm{mg} / \mathrm{ml}$ collagenase type II (Sigma-Aldrich) in Hanks' Balanced Salt Solution (HBSS) (+) (Thermo Fischer Scientific, Waltham, MA, USA) for $10 \mathrm{~min}$ at $34^{\circ} \mathrm{C}$. After tubule sedimentation, the supernatant containing the testicular interstitial cells was collected and centrifuged to obtain a cell pellet. Tubules without both germ cells and interstitial cells were also collected for experiments.

\section{Cell culture}

Mouse GS cells were originally established from mouse pups with DBA/2 background and kindly provided by Dr T Shinohara's laboratory. The culture conditions used were as described previously [17]. Briefly, GS cells were cultured on mitomycin C (Nacalai Tesque Inc.)-inactivated mouse embryonic feeder cells with StemPro34 SFM-based medium (Thermo Fischer Scientific) supplemented with $1 \%$ fetal bovine serum (Biowest, Nuaillé, France), $10 \mathrm{ng} / \mathrm{mL}$ rat GDNF (Peprotech, London, UK), and $10 \mathrm{ng} / \mathrm{ml}$ human FGF2 (Peprotech). Before experiments, GS cells were maintained on laminin-coated dishes (Corning, Corning, NY, USA) for more than 2 weeks and then subjected to analyses.

\section{Quantitative reverse transcription-polymerase chain reaction (RT-qPCR)}

Total RNA was extracted using Sepasol-RNA I Super G (Nacalai Tesque). Total RNA samples were subjected to cDNA synthesis using ReverTra Ace with gDNA remover (TOYOBO, Osaka, Japan). The cDNA samples were then analyzed by RT-qPCR using SYBR Premix Ex Taq II in combination with a Thermal Cycler Dice ${ }^{\circledR}$ Real Time System TP800 (TAKARA BIO Inc., Shiga, Japan). Reaction conditions were as follows: $95^{\circ} \mathrm{C}$ for $1 \mathrm{~min}$, followed by 40 cycles of $95^{\circ} \mathrm{C}$ for $15 \mathrm{sec}, 55^{\circ} \mathrm{C}$ for $30 \mathrm{sec}$, and $72^{\circ} \mathrm{C}$ for $30 \mathrm{sec}$, further followed by a melting curve program. Each RT-qPCR cycle was run in duplicate. The cycle threshold $(\mathrm{Ct})$ values were calculated by a second derivative maximum method using Thermal Cycler Dice ${ }^{\circledR}$ Real Time System Software Version 5.10 (TAKARA BIO). The standard curve method was applied to determine the absolute quantity. Standard cDNA stock for absolute quantitation was prepared from the PCR products using FastGene ${ }^{\mathrm{TM}} \mathrm{Gel} / \mathrm{PCR}$ Extraction Kits (Nippon Genetics, Tokyo, Japan). For data evaluation, values of the control group were set to 1.0 after normalization to Hprt expression levels. The primers used in this study are listed in Table 1. 
Table 1. Primers for RT-qPCR

\begin{tabular}{|c|c|c|}
\hline Gene & Forward primer & Reverse primer \\
\hline Acta2 & CTGACAGAGGCACCACTGAA & CATCTCCAGAGTCCAGCACA \\
\hline Aldh1a2 & CCATGACTTCCAGCGAGAT & TCTGAGTTCTGCCATTCATTG \\
\hline Cyp17al & CGTCTTTCAATGACCGGACT & CATAAACCGATCTGGCTGGT \\
\hline Cyp26al & TGACCCGCAATCTCTTCTCT & GAGGAGCTCTGTTGACGATTG \\
\hline$D d x 4$ & CAGGCAATGGTGACACTTACC & ATGGAGTCCTCATCCTCTGG \\
\hline$F g f 2$ & CCAACCGGTACCTTGCTATG & TATGGCCTTCTGTCCAGGTC \\
\hline FgfrlIIIb & CTTGCCGTATGTCCAGATCC & TCACAGCTGGTCTCTCTTCC \\
\hline FgfrlIIIc & AAGCACATCGAGGTGAACG & TCAACCATGCAGAGTGATGG \\
\hline Fgfr $2 I I I b$ & CCACATCCAGTGGATCAAGC & TCACATTGAACAGAGCCAGC \\
\hline Fgfr2IIIc & CCACATCCAGTGGATCAAGC & АТСТССТTСТСТСТCACAGGCG \\
\hline Fgfr $3 I I I b$ & GTGTACAGCGATGCACAGC & CACATTCTCACTGATCCAGG \\
\hline Fgfr3IIIc & CAACCAGACAGCCATTCTAGG & CATTGTGCAAGGACAGAACC \\
\hline Fgfr 4 & CAAGTGGTTCGTGCAGAGG & CATTCCACAATCACGTACAGG \\
\hline Gdnf & GCCACTTGGAGTTAATGTCC & CTTCGAGAAGCCTCTTACCG \\
\hline Hprt & GCTGGTGAAAAGGACCTCT & CACAGGACTAGAACACCTGC \\
\hline $\operatorname{Sox} 9$ & AGGAAGCTGGCAGACCAGTA & CGTTCTTCACCGACTTCCTC \\
\hline
\end{tabular}

\section{Histology}

For histological analysis, the collected testes were fixed in Bouin's solution (Sigma-Aldrich) for $12 \mathrm{~h}$ at $4^{\circ} \mathrm{C}$. After washing with $70 \%$ ethanol, the tissues were processed for routine histology, and paraffin wax-embedded sections were stained with hematoxylin and eosin. Images were captured under a light microscope (IX73; Olympus, Tokyo, Japan) equipped with a digital camera (DP73; Olympus). The numbers of tubule cross-sections with evidence of spermatogenesis, defined as the presence of at least two layers of germ cells in the entire circumference of the tubule, were counted. Tubules with multiple germ cell layers covering only part of the seminiferous tubule were not considered to be "true" spermatogenic tubules for this analysis [26].

\section{Statistical analyses}

Results are presented as the mean \pm standard error of the mean (SEM). Significant differences between means for single comparisons were determined using Student's $t$-test. Multiple comparison analyses were carried out using one-way analysis of variance followed by Tukey's honest significant difference test. $\mathrm{P}<0.05$ was considered statistically significant.

\section{Results}

Fgf2 is expressed in both germ cells and testicular somatic cells To identify the origin of FGF2 in the testis, we performed RT-qPCR analysis. Germ cell depletion by busulfan treatment, experimental cryptorchidism, and W mutation resulted in loss of $D d x 4$ and upregulation of $G d n f$ expression in the testis (Fig. 1A). This is consistent with the fact that Sertoli cells produce GDNF [27-29]. By contrast, Fgf2 expression was downregulated by germ cell depletion (Fig. 1A), suggesting that germ cells are the major population that express $F g f 2$. However, we still observed considerable $F g f 2$ expression in germ cell-depleted testes. For further exploring $F g f 2$-expressing cells in the testes, germ cell-depleted testes (termed "Bus testis") were divided into testicular interstitial cells (ICs) and seminiferous tubules (Tubs) by collagenase digestion (Fig. 1B). RT-qPCR revealed that ICs were enriched in Cyp 17al-expressing Leydig cells [30], whereas Tubs were enriched in Sertoli cells and PMCs (Fig. 1C) [31, 32]. Although ICs showed higher expression than Tubs, we found that both populations expressed $F g f 2$ (Fig. 1C).

We also explored the cellular target of FGF2 in the testes. In this experiment, we used mouse GS cells as an in vitro model of SSCs and/or undifferentiated spermatogonia. RT-qPCR revealed that both GS cells and testicular somatic cells expressed Fgfrl (Fig. 1D). Fgfr 2/3/4 were also expressed in Tubs and ICs. These results suggest that FGF2 targets not only SSCs and/or undifferentiated spermatogonia but also testicular somatic cells.

\section{Fgf2 regulation in the testis}

It is known that the hypothalamic-pituitary (HP) axis regulates testicular functions [33]. To examine the role of HP axis in the regulation of testicular $F g f 2$, we assessed the effect of functional disruption of the pituitary gland. After hypophysectomy, Cyp 17a1 [a gene expressed in Leydig cells and regulated by luteinizing hormone (LH)] expression was diminished just 1 week after the operation, the germ cell population gradually declined, and the testis weight decreased, as compared with that in the sham-operated group (Fig. 2A, B). These data confirmed that hypophysectomy was performed successfully. In this situation, $F g f 2$ and $G d n f$ exhibited distinct expression dynamics. $F g f 2$ expression was initially upregulated and then downregulated to $40 \%$ of control levels by the end of 7 weeks, suggesting that $F g f 2$ expression is somehow affected by the function of the HP axis. Aldh1a2, Cyp26a1, and Ddx4 exhibited similar expression dynamics to those of $F g f 2$. On the other hand, $G d n f$ exhibited step-wise upregulation from 1 to 7 weeks post operation (Fig. 2B). Although the effects of adrenalectomy and thyroidectomy were examined, these interventions did not affect spermatogenesis or the expression of $F g f 2$ or $G d n f$ at 7 weeks post-surgery (Fig. 2C-F). These results demonstrated that HP axis-mediated regulation of $\mathrm{Fgf} 2$ 

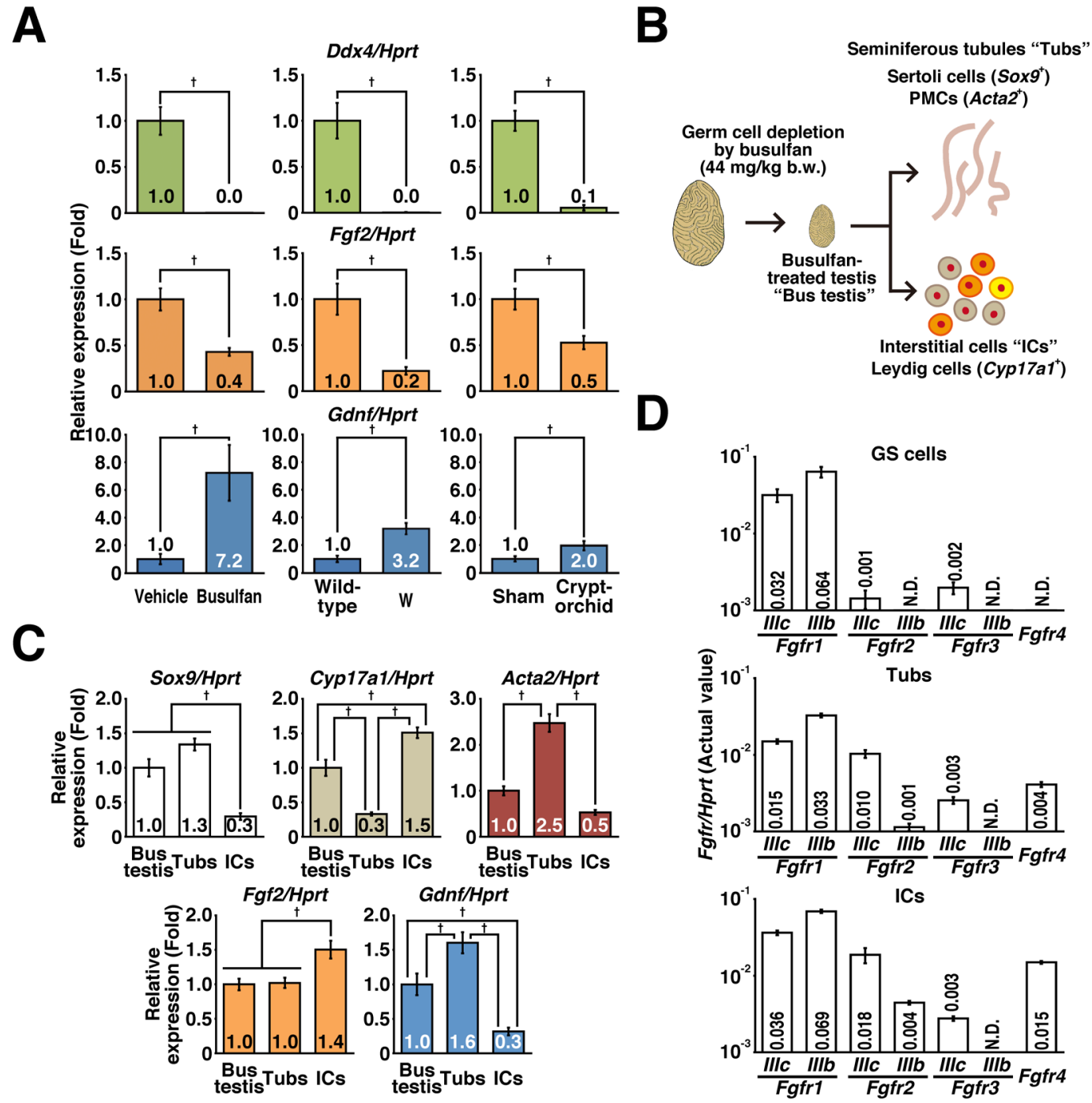

Fig. 1. Identification of $F g f 2$-expressing cells and their targets in the testes. (A) RT-qPCR results: the effects of busulfan treatment (44 mg/kg body weight) on mice with a congenital spermatogenic defect (W mutation), and experimental cryptorchidism were analyzed. After normalization to Hprt expression level, the values of control groups (vehicle, sham, and wild-type groups for the busulfan, cryptorchid, and W groups, respectively) were set to 1.0 ( $\mathrm{n}=5-8$ for each group). The testes were harvested at 4 weeks (busulfan treatment) or 7 weeks (experimental cryptorchidism) after treatment and subjected to analysis. W mouse testes were harvested at 8 weeks of age. Age-matched mice were used as control samples in each experiment. (B) Preparation of seminiferous tubules and testicular interstitium. The testes were harvested at 4 weeks after treatment with $44 \mathrm{mg} / \mathrm{kg}$ body weight busulfan (Bus testes) and subjected to collagenase digestion to separate interstitial cells (ICs) from the seminiferous tubules (Tubs). The resulting populations were subjected to RT-qPCR. (C) Gene expression of niche components. After normalization to Hprt expression level, the value of the "Bus testis" group was set to 1.0 ( $\mathrm{n}=6$ for each group). (D) Fgfr expression in GS cells and niche components. The value of each sample is indicated after normalization to Hprt expression $(\mathrm{n}=3$ independent cultures of GS cells and $\mathrm{n}=6$ for Tubs and ICs). Results are shown as the mean \pm SEM. Daggers $(\dagger)$ indicate statistically significant differences between treatment groups $(\mathrm{P}<0.05)$.

and $G d n f$ does not require the function of the thyroid or adrenal glands.

We also examined the effect of RA treatment on the expression of testicular $F g f 2$. A single intraperitoneal injection of all-trans RA at a dose of $750 \mu \mathrm{g} /$ body to adult mice was effective to induce activation of the RA signal-related gene, Cyp26a1, in the testes (Fig. 2G). In this situation, although $G d n f$ expression was downregulated, Fgf2 expression was not affected (Fig. 2G). Taken together, these results demonstrated that the control mechanisms of Fgf2 in the testes are distinct from those of $G d n f$.
Expression dynamics of Fgf2 and Gdnf in the testes

We compared the expression dynamics of Fgf2 and Gdnf in the mouse testes under normal physiological conditions. RT-qPCR revealed that $G d n f$ expression was downregulated with age, while $F g f 2$ expression remained constant (Fig. 3). In addition, the expression dynamics of $F g f 2$ under conditions of testicular regeneration were also investigated. Treatment with a low dose $(15 \mathrm{mg} / \mathrm{kg}$ body weight) of busulfan permitted testicular regeneration, as diagnosed by temporary loss and subsequent recovery of testis weight and 
A
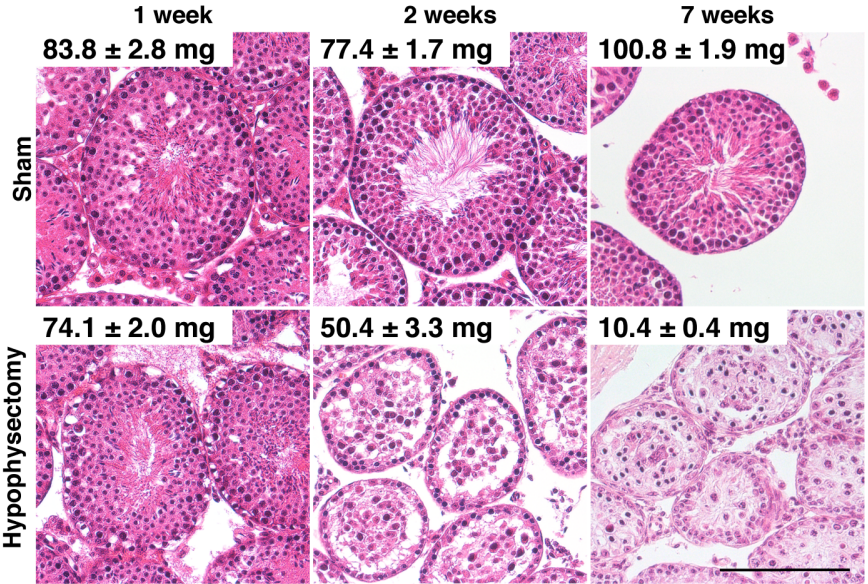

B
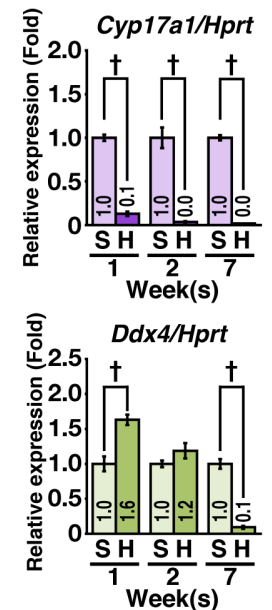

S: Sham H: Hypophysectomy
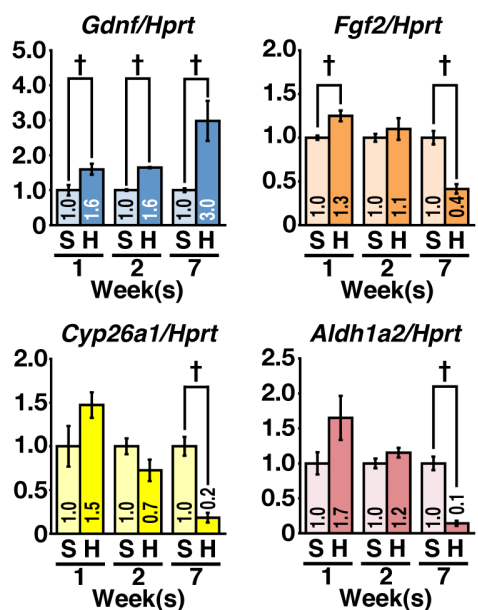

C

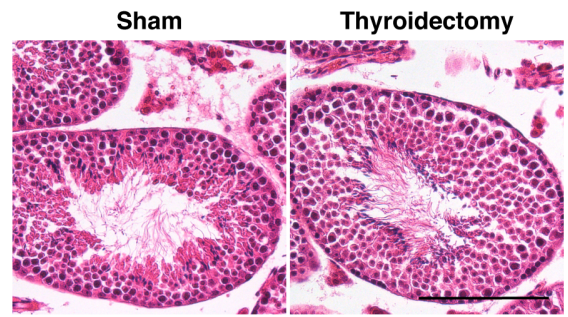

E

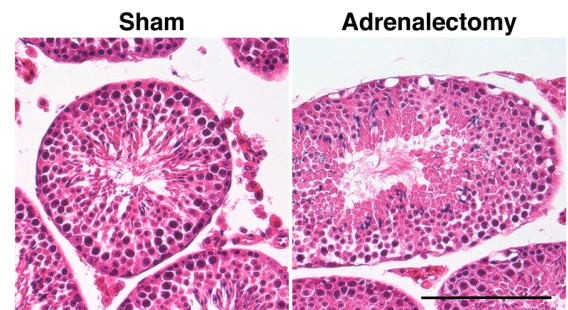

D
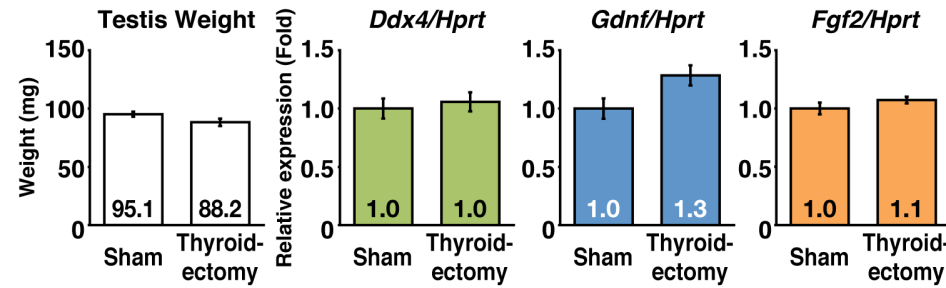

$\mathbf{F}$
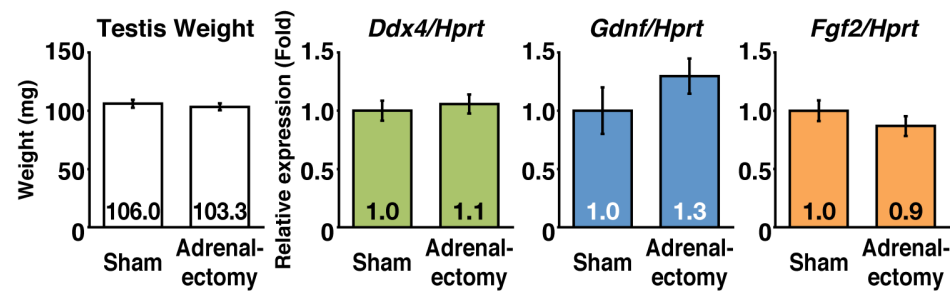

G
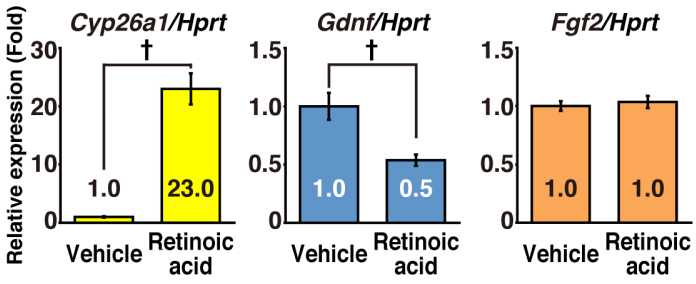

Fig. 2. Mechanisms regulating $F g f 2$ and $G d n f$ expression in the testes. Effects of endocrine organs and RA signaling were examined. (A and B) Effect of hypophysectomy on Fgf2 and Gdnf expression in the testis. (A) Testis weight and histology. Hypophysectomized and sham-operated mouse testes were prepared for histological analysis at 1,2 , and 7 weeks post operation. Paraffin wax-embedded sections were stained with hematoxylin and eosin. Testis weights at each time point are shown in the inserts as the mean \pm SEM (mg). (B) qPCR analysis. Gene expression profiles were analyzed. After normalization to Hprt expression, the value of the "Sham" group in each time-point was set to 1.0 ( $\mathrm{n}=3-4$ for each group). (C and D) Effect of thyroidectomy on $F g f 2$ and $G d n f$ expression in the testis. (C) Histological changes. Thyroidectomized and sham-operated mouse testes were prepared for histological analysis at 7 weeks post operation. Paraffin wax-embedded sections were stained with hematoxylin and eosin. (D) Effect of thyroidectomy. After normalization to Hprt expression, the value of the "Sham" group was set to 1.0 (sham, $\mathrm{n}=4$; thyroidectomy, $\mathrm{n}$ =5). (E and F) Effect of adrenalectomy on Fgf2 and Gdnf expression in the testis. (E) Histological changes. Adrenalectomized and sham-operated mouse testes were prepared for histological analysis at 7 weeks post operation. Paraffin wax-embedded sections were stained with hematoxylin and eosin. (F) Effect of adrenalectomy. After normalization to Hprt expression, the value of the "Sham" group was set to 1.0 (sham, $\mathrm{n}=4$; adrenalectomy, $\mathrm{n}=5$ ). (G) Effect of RA treatment. 8-week-old male B6 mice were injected intraperitoneally with $750 \mu \mathrm{g}$ RA. The testes were collected $11 \mathrm{~h}$ after treatment, and analyzed by RT-qPCR ( $\mathrm{n}=4$ for each group). Bar $=100 \mu \mathrm{m}$ (A, C, E). Results are shown as the mean \pm SEM. Daggers $(\dagger)$ indicate statistically significant differences between treatment groups $(\mathrm{P}<0.05)$. 


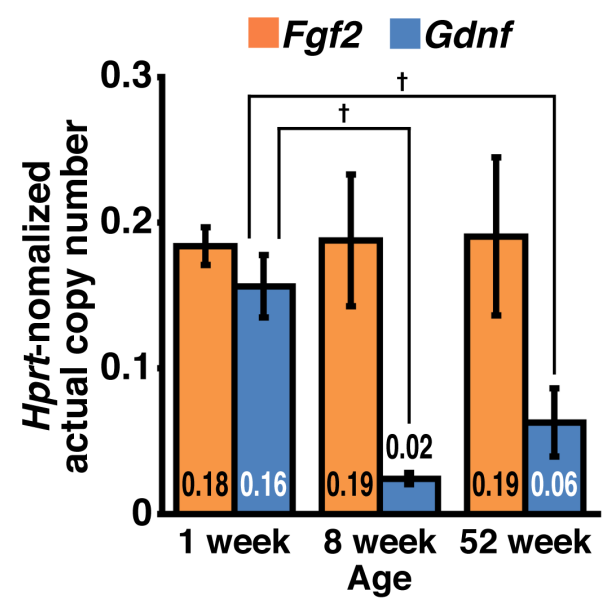

Fig. 3. Expression dynamics of $F g f 2$ and $G d n f$ in the testes. The testes from immature (1-week-old) and adult (8- and 52-week-old) B6 mice were subjected to RT-qPCR. After normalization to Hprt expression, the values of each sample are indicated directly (n $=3-5$ for each group). Results are shown as the mean \pm SEM. Daggers $(\dagger)$ indicate statistically significant differences between treatment groups $(\mathrm{P}<0.05)$.

spermatogenesis (Fig. 4A-C). Consistent with a previous report [34], $G d n f$ expression was upregulated temporarily and then reverted to normal levels. Although treatment-dependent upregulation of $\mathrm{Fgf} 2$ expression was also observed, the time to reversion was shorter than that for $G d n f$ (Fig. 4D).

\section{Discussion}

GDNF is essential for the maintenance and self-renewal of SSCs in the germline niche $[4,16]$. Moreover, FGF2 was also shown to act as another bona fide self-renewal factor for SSCs in vitro [24]. These suggest that both FGF2 and GDNF regulate SSC self-renewal in the germline niche. However, our previous study showed that F-SPG are distinct from G-SPG in that they possess more differentiated characteristics (higher expression of the differentiation marker KIT, lower SSC activity); F-SPG could survive and proliferate without activation of the MAPK signaling pathway, whereas G-SPG requires MAPK activation [24]. To clarify these differences in the roles of FGF2 and GDNF in the testis, we examined the spatiotemporal dynamics of these factors.

Previous studies on the identification of FGF2-producing cells have yielded inconsistent results. Some studies demonstrated FGF2 production in Sertoli cells, while others demonstrated that germ cells produced this protein. Smith et al. detected FGF2 production in cultured rat Sertoli cells [35]. Mullaney and Skinner, and Tadokoro et al. obtained similar results [36, 37]. By contrast, Han et al. demonstrated germ cell production of FGF2 [38]. In their study, FGF2 production was detected from cellular lysates, tissue extracts, or culture supernatants using biochemical approaches (column chromatography, western blotting, or immunohistochemistry, respectively). These contrasting reports include mutual concerns in analytical methods. One of them is the culture-mediated effect. Cell culture often causes adaptation-mediated phenotypic alterations. In addition, rapid expansion of other contaminating cell populations can affect Sertoli cells in vitro. Another concern is the molecular characteristic of FGF2. It is well-known that FGF2 is prone to bind to heparan sulfate proteoglycans (HSPGs), which are abundant in the extracellular matrix and at the cell surface. Therefore, a biochemical approach might help detect FGF2 molecules produced ectopically and forming complexes with HSPGs on the Sertoli cell surface. Serum used in the culture medium might also provide FGF2 supplementation. Given these circumstances, we reconsidered the source of FGF2 production in the testis. For this purpose, we employed RT-qPCR to avoid false detection of ectopically produced FGF2 and demonstrated that busulfan-mediated germ cell depletion decreased $F g f 2$ expression in the testis. These results suggest that Sertoli cells are not necessarily the major FGF2-producing cells, and that germ cells could be a source of FGF2. However, other possibilities remain. Busulfan treatment might affect $F g f 2$ expression in the testicular somatic cells and deprivation of germ cell-derived signals (e.g. JAG1-NOTCH2 signal) might attenuate $F g f 2$ expression in the testicular somatic cells [39, 40]. To assess these possibilities, we exploited mice with a congenital defect (W) and those with experimental cryptorchidism in which spermatogonia are maintained [37]. However, both the W mutation and cryptorchidism resulted in reduced $F g f 2$ expression, as seen in the case of busulfan-mediated germ cell depletion, demonstrating that reduced expression of $F g f 2$ is not caused by busulfan treatment or loss of germ cell-derived signals. Although these data strongly suggest that the germ cell population is the major source of FGF2 in the testis, it remains to be elucidated which subset of the germ cells produces FGF2. Experimental cryptorchidism-mediated decline of $F g f 2$ expression suggests that differentiated germ cells rather than spermatogonia strongly express $F g f 2$. On the other hand, Zhang et al. demonstrated that cultured SSCs produce FGF2 [41]. We also found that non-germ cell populations forming seminiferous tubules and interstitial compartment in the testes showed non-negligible $F g f 2$ expression. However, the actual subset of testicular somatic cells remains to be identified. The seminiferous tubules we isolated expressed not only Sox 9 but also Acta2, suggesting the significant enrichment of Sertoli cells and PMCs. On the other hand, the testicular interstitium was shown to be enriched in Leydig cells. Blood vessels might also be included in the interstitial compartment. To conclude, it is most appropriate to purify the subsets of testis cells using fluorescence-activated cell sorting/magnetic-activated cell sorting in combination with a reporter strain animal $[42,43]$.

It is well known that the HP axis regulates testicular function via the actions of follicle stimulating hormone (FSH) and LH. In addition, the thyroid and adrenal glands have been suggested to regulate testicular function in rats $[44,45]$. Although thyroidectomy and adrenalectomy did not affect the expression of self-renewal factors in the testis, a gradual decrease in $F g f 2$ expression was observed in hypophysectomized mice. Rapid downregulation of Cyp 17 al expression, which is induced in Leydig cells by LH stimulus and is indispensable for testosterone synthesis, confirmed successful hypophysectomy. Considering the gradual decrease in $D d x 4$ expression and rapid decrease in Cyp $17 a 1$ expression after hypophysectomy, a decrease in $F g f 2$ expression is likely because of the reduction in the $F g f$-expressing germ cell population, rather than loss of endocrine signals from the HP axis. Moreover, hypophysectomy enhanced 
A

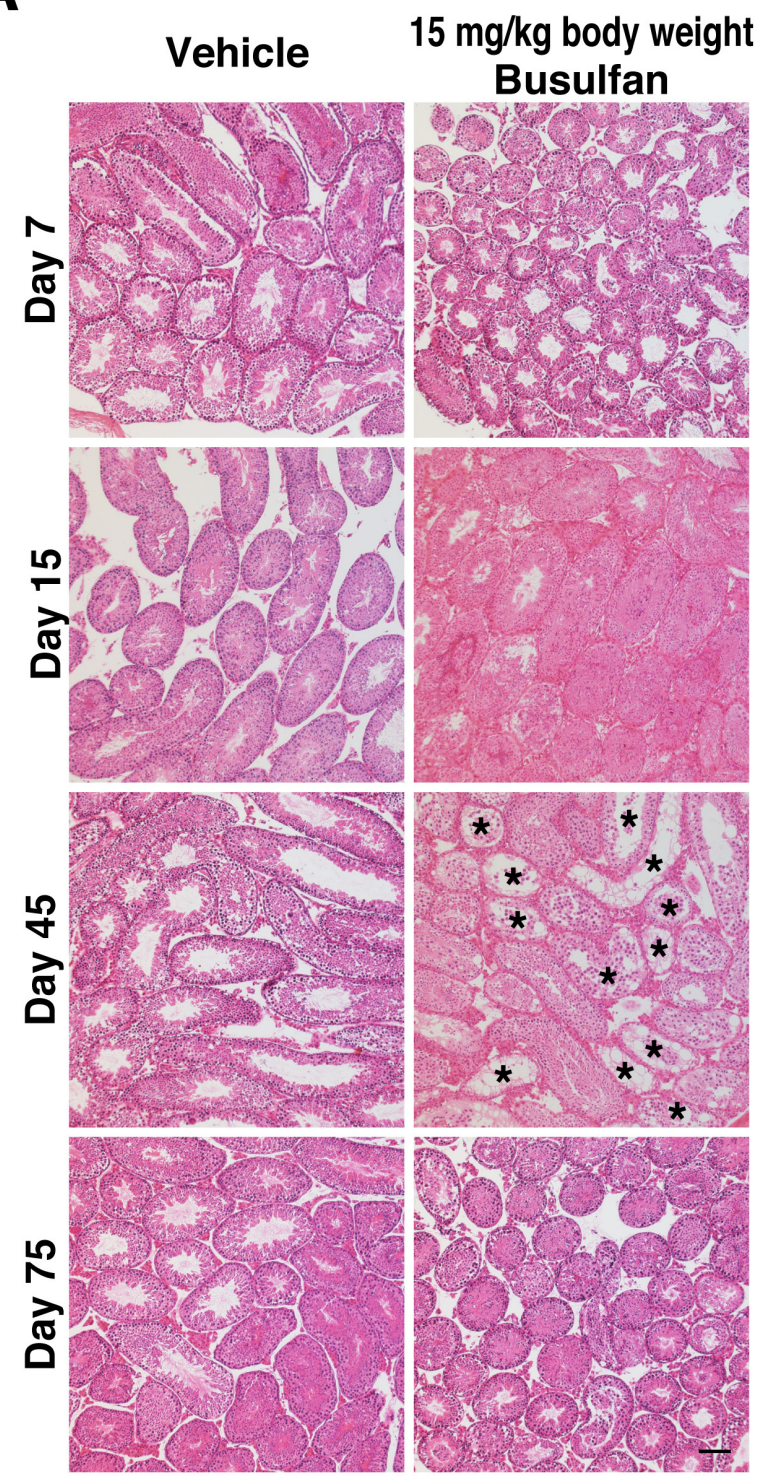

B
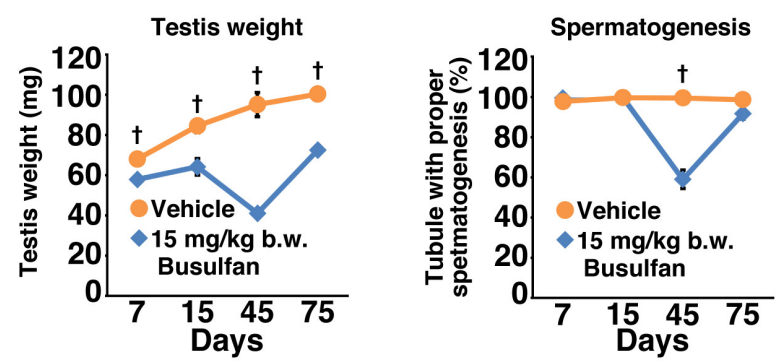

D

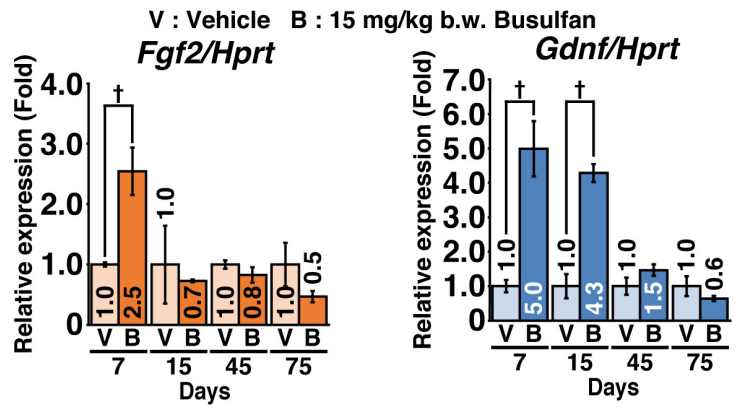

Fig. 4. Expression dynamics of $F g f 2$ and $G d n f$ during testicular regeneration Mice testes treated with $15 \mathrm{mg} / \mathrm{kg}$ body weight busulfan at 6 weeks of age were analyzed at the indicated time points. (A) Histological changes induced by busulfan treatment $(\mathrm{n}=3$ for each group). Asterisks $(*)$ indicate tubules with spermatogenic arrest. (B) Testis weight $(\mathrm{n}=3$ for each group). (C) Spermatogenic arrest caused by busulfan treatment. The proportion of tubules with active spermatogenesis was evaluated $(n=3$ for each group). The total numbers of tubules counted were 1130 and 1245 for vehicle- and busulfan-treated testes, respectively. (D) Expression of $F g f 2$ and $G d n f$ during testicular regeneration. After normalization to Hprt expression, the value of the vehicle $(\mathrm{V})$ control group at each time point was set to 1.0 ( $\mathrm{n}=3$ for each group); $\mathrm{B}$, busulfan. Results are shown as the mean \pm SEM. Bar $=100 \mu \mathrm{m}(\mathrm{A})$. Daggers $(\dagger)$ indicate statistically significant differences between treatment groups $(\mathrm{P}<0.05)$. testicular $G d n f$ expression in a step-wise manner. This upregulation of testicular $G d n f$ expression is consistent with the findings of previous reports [14, 46-48]. Considering that Lhcgr knockout mice, but not Fshb knockout mice, exhibited increased expression of $G d n f$, pituitary gland-derived LH signals might suppress $G d n f$ expression in the testis [14]. It is intriguing that hypophysectomy upregulated $G d n f$ expression in a step-wise manner. We also found that Cyp26a1 and Aldhla 2 expression was significantly suppressed at 7 weeks after hypophysectomy. Cyp26al encodes a RA-metabolizing enzyme and is induced by RA in the testes (Fig. 2G). RA production is dependent on the germ cell-expressed enzyme encoded by Aldhla2 [49, 50]. Hasegawa et al. also demonstrated that RA treatment attenuated testicular $G d n f$ expression [51]. Based on these results, the upregulated expression of $G d n f$ in the second step might be due to the reduction of RA signal. Although our results regarding hypophysectomy are not consistent with those of Chen et al., who found that testosterone induced GDNF production from PMCs in vitro [52], it is possible that experimental differences (in vivo vs. in vitro studies) might have caused these contradictory results. On the other hand, we also found that $F g f 2$ expression was not affected by RA treatment, but $G d n f$ expression was suppressed. Gdnf is expressed in Sertoli cells and PMCs [4, 5, 52]. In addition, the expression level of this gene oscillates in the seminiferous epithelial cycle [53]. Hogarth et al. demonstrated the periodic oscillatory change of RA content in the seminiferous tubule [54]. Hasegawa et al. showed that RA administration suppresses Gdnf expression in the testes of mice [51]. We also obtained similar results (Fig. 2G). These data suggest that the oscillatory expression pattern of $G d n f$ is causally related with RA oscillations. By contrast, $F g f 2$ expression was not affected by RA administration (Fig. 2G), despite the fact that RA receptors are expressed in both germ and 
somatic cells, which have been demonstrated to express Fgf2 [55]. Also, the HP axis might not directly contribute to the regulation of Fgf2 in the testis (Fig. 2B). Taken together, these data suggested that the mechanism of $F g f 2$ regulation in the testis is distinct from that of $G d n f$, raising the possibility that FGF2 and GDNF might act at different domains and/or timings in the testis.

We found that $G d n f$ expression was attenuated with aging, while strong expression of $F g f 2$ in the pup testes was maintained even after the prepubertal stage. Germ cell depletion also changes the expression pattern of these genes, in that $F g f 2$ expression is decreased, while $G d n f$ expression is increased (Fig. 1A). $G d n f / F g f 2$ ratio in the testes seems higher in the prepubertal stages and germ cell-deficient conditions, as compared to that in normal adult testes. Given that the expression mechanism of $F g f 2$ is distinct from that of $G d n f$, these genes should exhibit differential expression patterns in the testis. Our previous study demonstrated that F-SPG exhibited more differentiated characteristics than G-SPG [24]. These observations raise the possibility that fluctuation in the $G d n f / F g f 2$ ratio along the seminiferous tubule might affect the action of SSCs and/or undifferentiated spermatogonia in the germline niche.

Our previous report demonstrated that FGF2 contributes to maintaining the SSC activity of GS cells and F-SPG, both of which express genes encoding FGF2 receptors [17, 24], suggesting that SSCs in vivo can be a target of this molecule. In this study, we also found that testicular somatic cells express Fgfr genes, raising the possibility that FGF2 might act on these cells. Somatic cells in the tubules (Sertoli cells and PMCs) express $G d n f[4,5,52]$. Leydig cells are reported to produce CSF1 $[8,9]$. Germ cell- and/or testicular somatic cell-derived FGF2 might regulate the self-renewal of SSCs in vivo not only in a direct manner, but also in an indirect manner by regulating the expression of self-renewal factors in the germline niche. On the other hand, these somatic cells simultaneously contribute to the synthesis and metabolism of RA $[55,56]$. Therefore, FGF2 might also contribute to the regulation of RA action in the testis for proper spermatogenesis.

We exploited low-dose busulfan administration as a model for testicular regeneration [34, 57]. Although high-dose busulfan might also induce regeneration, we thought that it would be better to avoid complete destruction of the germ cell population to reproduce the process of testicular regeneration precisely. This procedure results in testicular regeneration within 70 days [57]. Upon treatment, both factors exhibited temporal upregulation, raising the possibility that these factors contribute to regenerative action in the testis. Although both germ cells and testicular somatic cells can contribute to this action, we did not identify which population contributed to the upregulation of $F g f 2$ expression in the testis under regenerative conditions. To understand the mechanism of $F g f 2$ regulation in the testis, both identification of FGF2-producing cells and molecular dissection of the $F g f$-expressing mechanisms in each cell type are required.

Although both FGF2 and GDNF are bona fide self-renewal factors for SSCs in vitro, FGF2 provides outcomes for cultured undifferentiated spermatogonia that are distinct from those provided by GDNF in vitro (e.g., SSC frequency and expression of differentiation markers) [24]. These data suggest that FGF2 plays a role that is distinct from that of GDNF in the germline niche. Our present study also supports this idea by raising the possibility that FGF2 and GDNF act at different times and/or regions in the testis. This study suggests the existence of functionally distinct "FGF2-dominant niche" and "GDNF-dominant niche". The former might permit spermatogonial differentiation in the adult testes and the latter might contribute to expansion of undifferentiated spermatogonia in the prepubertal stages and during testicular regeneration. Moreover, these niches might change their domain size depending on the developmental/aging stage, seminiferous epithelial cycle, and ectopic cues, such as testicular damage. The next issue to be clarified is how the spatiotemporal balance of action of these factors is regulated.

\section{Acknowledgments}

We thank T Shinohara (Kyoto University) for generously providing GS cells, F Suito (University of Tokyo) for assistance with image analysis using Image J software, and H Ogawa, Y Kawahara, H Adachi, A Tsuchimoto, T Abe, D Takemasa, A Miura, and A Nakano of ST's laboratory for technical assistance and helpful discussions. This work was funded by JSPS KAKENHI (JP16H05046), the Sumitomo Foundation, the Naito Foundation, the Ito Foundation, the Hokuto Foundation for Bioscience, the Japan Health Foundation, the Mochida Memorial Foundation for Medical and Pharmaceutical Research, the Ichiro Kanehara Foundation for the Promotion of Medical Sciences and Medical Care, the Uehara Memorial Foundation, the Suzuken Memorial Foundation, the Takeda Science Foundation (to ST), and the Foundation of Nagano Prefecture Science Promotion (to KM). We thank James Cummins, PhD, from EDANZ Group (www.edanzediting. com/ac) for editing a draft of this manuscript.

\section{References}

1. de Rooij DG, Russell LD. All you wanted to know about spermatogonia but were afraid to ask. J Androl 2000; 21: 776-798. [Medline]

2. de Rooij DG, Grootegoed JA. Spermatogonial stem cells. Curr Opin Cell Biol 1998; 10: 694-701. [Medline] [CrossRef]

3. Shinohara T, Avarbock MR, Brinster RL. beta1- and alpha6-integrin are surface markers on mouse spermatogonial stem cells. Proc Natl Acad Sci USA 1999; 96: 5504-5509. [Medline] [CrossRef]

4. Meng X, Lindahl M, Hyvönen ME, Parvinen M, de Rooij DG, Hess MW, RaatikainenAhokas A, Sainio K, Rauvala H, Lakso M, Pichel JG, Westphal H, Saarma M, Sariola H. Regulation of cell fate decision of undifferentiated spermatogonia by GDNF. Science 2000; 287: 1489-1493. [Medline] [CrossRef]

5. Chen LY, Willis WD, Eddy EM. Targeting the Gdnf Gene in peritubular myoid cells disrupts undifferentiated spermatogonial cell development. Proc Natl Acad Sci USA 2016; 113: 1829-1834. [Medline] [CrossRef]

6. Yoshida S, Sukeno M, Nabeshima Y. A vasculature-associated niche for undifferentiated spermatogonia in the mouse testis. Science 2007; 317: 1722-1726. [Medline] [CrossRef]

7. Hara K, Nakagawa T, Enomoto H, Suzuki M, Yamamoto M, Simons BD, Yoshida S. Mouse spermatogenic stem cells continually interconvert between equipotent singly isolated and syncytial states. Cell Stem Cell 2014; 14: 658-672. [Medline] [CrossRef]

8. DeFalco T, Potter SJ, Williams AV, Waller B, Kan MJ, Capel B. Macrophages contribute to the spermatogonial niche in the adult testis. Cell Reports 2015; 12: 1107-1119. [Medline] [CrossRef]

9. Oatley JM, Oatley MJ, Avarbock MR, Tobias JW, Brinster RL. Colony stimulating factor 1 is an extrinsic stimulator of mouse spermatogonial stem cell self-renewal. Development 2009; 136: 1191-1199. [Medline] [CrossRef]

10. Hasegawa K, Saga Y. FGF8-FGFR1 signaling acts as a niche factor for maintaining undifferentiated spermatogonia in the mouse. Biol Reprod 2014; 91: 145. [Medline] [CrossRef]

11. Lu N, Sargent KM, Clopton DT, Pohlmeier WE, Brauer VM, McFee RM, Weber JS, Ferrara N, Silversides DW, Cupp AS. Loss of vascular endothelial growth factor A (VEGFA) isoforms in the testes of male mice causes subfertility, reduces sperm numbers, and alters expression of genes that regulate undifferentiated spermatogonia. Endocrinology 
2013; 154: 4790-4802. [Medline] [CrossRef]

12. Yeh JR, Zhang $\mathbf{X}$, Nagano MC. Indirect effects of $\mathrm{Wnt} 3 \mathrm{a} / \beta$-catenin signalling support mouse spermatogonial stem cells in vitro. PLoS ONE 2012; 7: e40002. [Medline] [CrossRef]

13. Yeh JR, Zhang X, Nagano MC. Wnt5a is a cell-extrinsic factor that supports self-renewal of mouse spermatogonial stem cells. J Cell Sci 2011; 124: 2357-2366. [Medline] [CrossRef]

14. Tanaka T, Kanatsu-Shinohara M, Lei Z, Rao CV, Shinohara T. The luteinizing hormone-testosterone pathway regulates mouse spermatogonial stem cell self-renewal by suppressing WNT5A expression in Sertoli cells. Stem Cell Rep 2016; 7: 279-291. [Medline] [CrossRef]

15. Takase HM, Nusse R. Paracrine Wnt/ $\beta$-catenin signaling mediates proliferation of undifferentiated spermatogonia in the adult mouse testis. Proc Natl Acad Sci USA 2016; 113: E1489-E1497. [Medline] [CrossRef]

16. Yomogida K, Yagura Y, Tadokoro Y, Nishimune Y. Dramatic expansion of germinal stem cells by ectopically expressed human glial cell line-derived neurotrophic factor in mouse Sertoli cells. Biol Reprod 2003; 69: 1303-1307. [Medline] [CrossRef]

17. Kanatsu-Shinohara M, Ogonuki N, Inoue K, Miki H, Ogura A, Toyokuni S, Shinohara T. Long-term proliferation in culture and germline transmission of mouse male germline stem cells. Biol Reprod 2003; 69: 612-616. [Medline] [CrossRef]

18. Kanatsu-Shinohara M, Ogonuki N, Iwano T, Lee J, Kazuki Y, Inoue K, Miki H, Takehashi M, Toyokuni S, Shinkai Y, Oshimura M, Ishino F, Ogura A, Shinohara T. Genetic and epigenetic properties of mouse male germline stem cells during long-term culture. Development 2005; 132: 4155-4163. [Medline] [CrossRef]

19. Nagano M, Avarbock MR, Brinster RL. Pattern and kinetics of mouse donor spermatogonial stem cell colonization in recipient testes. Biol Reprod 1999; 60: 1429-1436. [Medline] [CrossRef]

20. Kanatsu-Shinohara M, Miki H, Inoue K, Ogonuki N, Toyokuni S, Ogura A, Shinohara T. Long-term culture of mouse male germline stem cells under serum-or feeder-free conditions. Biol Reprod 2005; 72: 985-991. [Medline] [CrossRef]

21. Kanatsu-Shinohara M, Toyokuni S, Shinohara T. Genetic selection of mouse male germline stem cells in vitro: offspring from single stem cells. Biol Reprod 2005; 72: 236-240. [Medline] [CrossRef]

22. Kanatsu-Shinohara M, Shinohara T. Spermatogonial stem cell self-renewal and development. Annu Rev Cell Dev Biol 2013; 29: 163-187. [Medline] [CrossRef]

23. Jijiwa M, Kawai K, Fukihara J, Nakamura A, Hasegawa M, Suzuki C, Sato T, Enomoto A, Asai N, Murakumo Y, Takahashi M. GDNF-mediated signaling via RET tyrosine 1062 is essential for maintenance of spermatogonial stem cells. Genes Cells 2008; 13: 365-374. [Medline] [CrossRef]

24. Takashima S, Kanatsu-Shinohara M, Tanaka T, Morimoto H, Inoue K, Ogonuki N, Jijiwa M, Takahashi M, Ogura A, Shinohara T. Functional differences between GDNFdependent and FGF2-dependent mouse spermatogonial stem cell self-renewal. Stem Cell Rep 2015; 4: 489-502. [Medline] [CrossRef]

25. Nishimune Y, Aizawa S, Komatsu T. Testicular germ cell differentiation in vivo. Fertil Steril 1978; 29: 95-102. [Medline] [CrossRef]

26. Takashima S, Takehashi M, Lee J, Chuma S, Okano M, Hata K, Suetake I, Nakatsuji N, Miyoshi H, Tajima S, Tanaka Y, Toyokuni S, Sasaki H, Kanatsu-Shinohara M, Shinohara T. Abnormal DNA methyltransferase expression in mouse germline stem cells results in spermatogenic defects. Biol Reprod 2009; 81: 155-164. [Medline] [CrossRef]

27. Trupp M, Rydén M, Jörnvall H, Funakoshi H, Timmusk T, Arenas E, Ibáñez CF. Peripheral expression and biological activities of GDNF, a new neurotrophic factor for avian and mammalian peripheral neurons. J Cell Biol 1995; 130: 137-148. [Medline] [CrossRef]

28. Hellmich HL, Kos L, Cho ES, Mahon KA, Zimmer A. Embryonic expression of glial cell-line derived neurotrophic factor (GDNF) suggests multiple developmental roles in neural differentiation and epithelial-mesenchymal interactions. Mech Dev 1996; 54: 95-105. [Medline] [CrossRef]

29. Golden JP, DeMaro JA, Osborne PA, Milbrandt J, Johnson EM Jr. Expression of neurturin, GDNF, and GDNF family-receptor mRNA in the developing and mature mouse. Exp Neurol 1999; 158: 504-528. [Medline] [CrossRef]

30. Wang GM, OShaughnessy PJ, Chubb C, Robaire B, Hardy MP. Effects of insulin-like growth factor I on steroidogenic enzyme expression levels in mouse leydig cells. Endocrinology 2003; 144: 5058-5064. [Medline] [CrossRef]

31. Nel-Themaat L, Jang CW, Stewart MD, Akiyama H, Viger RS, Behringer RR. Sertoli cell behaviors in developing testis cords and postnatal seminiferous tubules of the mouse. Biol Reprod 2011; 84: 342-350. [Medline] [CrossRef]

32. Campagnolo L, Russo MA, Puglianiello A, Favale A, Siracusa G. Mesenchymal cell precursors of peritubular smooth muscle cells of the mouse testis can be identified by the presence of the p75 neurotrophin receptor. Biol Reprod 2001; 64: 464-472. [Medline] [CrossRef]

33. Smith PE. Hypophysectomy and a replacement therapy in the rat. Am J Anat 1930; 45: 205-273. [CrossRef]

34. Zohni K, Zhang X, Tan SL, Chan P, Nagano MC. The efficiency of male fertility restoration is dependent on the recovery kinetics of spermatogonial stem cells after cytotoxic treatment with busulfan in mice. Hum Reprod 2012; 27: 44-53. [Medline] [CrossRef]
35. Smith EP, Hall SH, Monaco L, French FS, Wilson EM, Conti M. A rat Sertoli cell factor similar to basic fibroblast growth factor increases c-fos messenger ribonucleic acid in cultured Sertoli cells. Mol Endocrinol 1989; 3: 954-961. [Medline] [CrossRef]

36. Mullaney BP, Skinner MK. Basic fibroblast growth factor (bFGF) gene expression and protein production during pubertal development of the seminiferous tubule: folliclestimulating hormone-induced Sertoli cell bFGF expression. Endocrinology 1992; 131 2928-2934. [Medline] [CrossRef]

37. Tadokoro Y, Yomogida K, Ohta $\mathbf{H}$, Tohda A, Nishimune $\mathbf{Y}$. Homeostatic regulation of germinal stem cell proliferation by the GDNF/FSH pathway. Mech Dev 2002; 113: 29-39. [Medline] [CrossRef]

38. Han IS, Sylvester SR, Kim KH, Schelling ME, Venkateswaran S, Blanckaert VD, McGuinness MP, Griswold MD. Basic fibroblast growth factor is a testicular germ cell product which may regulate Sertoli cell function. Mol Endocrinol 1993; 7: 889-897. [Medline]

39. Garcia TX, Farmaha JK, Kow S, Hofmann MC. RBPJ in mouse Sertoli cells is required for proper regulation of the testis stem cell niche. Development 2014; 141: 4468-4478. [Medline] [CrossRef]

40. Garcia TX, Parekh P, Gandhi P, Sinha K, Hofmann MC. The NOTCH ligand JAG regulates GDNF expression in Sertoli cells. Stem Cells Dev 2017; 26: 585-598. [Medline] [CrossRef]

41. Zhang Y, Wang S, Wang X, Liao S, Wu Y, Han C. Endogenously produced FGF2 is essential for the survival and proliferation of cultured mouse spermatogonial stem cells. Cell Res 2012; 22: 773-776. [Medline] [CrossRef]

42. Kuroki S, Akiyoshi M, Ideguchi K, Kitano S, Miyachi H, Hirose M, Mise N, Abe K, Ogura A, Tachibana M. Development of a general-purpose method for cell purification using Cre/loxP-mediated recombination. Genesis 2015; 53: 387-393. [Medline] [CrossRef]

43. Shawki HH, Oishi H, Usui T, Kitadate Y, Basha WA, Abdellatif AM, Hasegawa K, Okada R, Mochida K, El-Shemy HA, Muratani M, Ogura A, Yoshida S, Takahashi S. MAFB is dispensable for the fetal testis morphogenesis and the maintenance of spermatogenesis in adult mice. PLoS ONE 2018; 13: e0190800. [Medline] [CrossRef]

44. Oncu M, Kavakli D, Gokcimen A, Gulle K, Orhan H, Karaoz E. Investigation on the histopathological effects of thyroidectomy on the seminiferous tubules of immature and adult rats. Urol Int 2004; 73: 59-64. [Medline] [CrossRef]

45. Silva EJ, Vendramini V, Restelli A, Bertolla RP, Kempinas WG, Avellar MC. Impact of adrenalectomy and dexamethasone treatment on testicular morphology and sperm parameters in rats: insights into the adrenal control of male reproduction. Andrology 2014 2: 835-846. [Medline] [CrossRef]

46. Ogawa T, Dobrinski I, Avarbock MR, Brinster RL. Leuprolide, a gonadotropinreleasing hormone agonist, enhances colonization after spermatogonial transplantation into mouse testes. Tissue Cell 1998; 30: 583-588. [Medline] [CrossRef]

47. Dobrinski I, Ogawa T, Avarbock MR, Brinster RL. Effect of the GnRH-agonist leuprolide on colonization of recipient testes by donor spermatogonial stem cells after transplantation in mice. Tissue Cell 2001; 33: 200-207. [Medline] [CrossRef]

48. Kanatsu-Shinohara M, Morimoto T, Toyokuni S, Shinohara T. Regulation of mouse spermatogonial stem cell self-renewing division by the pituitary gland. Biol Reprod 2004 70: 1731-1737. [Medline] [CrossRef]

49. Sugimoto R, Nabeshima Y, Yoshida S. Retinoic acid metabolism links the periodical differentiation of germ cells with the cycle of Sertoli cells in mouse seminiferous epithelium. Mech Dev 2012; 128: 610-624. [Medline] [CrossRef]

50. Arnold SL, Kent T, Hogarth CA, Griswold MD, Amory JK, Isoherranen N. Pharmacological inhibition of ALDH1A in mice decreases all-trans retinoic acid concentrations in a tissue specific manner. Biochem Pharmacol 2015; 95: 177-192. [Medline] [CrossRef]

51. Hasegawa K, Namekawa SH, Saga Y. MEK/ERK signaling directly and indirectly contributes to the cyclical self-renewal of spermatogonial stem cells. Stem Cells 2013; 31 2517-2527. [Medline] [CrossRef]

52. Chen LY, Brown PR, Willis WB, Eddy EM. Peritubular myoid cells participate in male mouse spermatogonial stem cell maintenance. Endocrinology 2014; 155: 4964-4974. [Medline] [CrossRef]

53. Grasso M, Fuso A, Dovere L, de Rooij DG, Stefanini M, Boitani C, Vicini E. Distribution of GFRA1-expressing spermatogonia in adult mouse testis. Reproduction 2012; 143 325-332. [Medline] [CrossRef]

54. Hogarth CA, Arnold S, Kent T, Mitchell D, Isoherranen N, Griswold MD. Processive pulses of retinoic acid propel asynchronous and continuous murine sperm production. Biol Reprod 2015; 92: 37. [Medline] [CrossRef]

55. Hogarth CA, Amory JK, Griswold MD. Inhibiting vitamin A metabolism as an approach to male contraception. Trends Endocrinol Metab 2011; 22: 136-144. [Medline] [CrossRef]

56. Hogarth CA, Evans E, Onken J, Kent T, Mitchell D, Petkovich M, Griswold MD CYP26 enzymes are necessary within the postnatal seminiferous epithelium for normal murine spermatogenesis. Biol Reprod 2015; 93: 19. [Medline] [CrossRef]

57. Kanatsu-Shinohara M, Toyokuni S, Morimoto T, Matsui S, Honjo T, Shinohara T Functional assessment of self-renewal activity of male germline stem cells following cytotoxic damage and serial transplantation. Biol Reprod 2003; 68: 1801-1807. [Medline] [CrossRef] 